\title{
Effects of imipramine on copulatory behavior of male rats*
}

\author{
DEIRDRE V. LOVECKY and DONALD A. DEWSBLRY \\ Liniversits of Florida. (iainessille. Fla. 326)l
}

Each of 16 male Long-Evans rats completed three tests of copulatory behavior: one following saline injection, one following administration of $10 \mathrm{mg} / \mathrm{kg}$ imipramine, and one following $25 \mathrm{mg} / \mathrm{kg}$ imipramine. Imipramine produced a prolongation of the intervals between intromissions within series and of the intervals between ejaculation and the resumption of copulation for all series tested. The number of intromissions required to attain ejaculation was reduced in all series. The effects were primarily attributable to the $25-\mathrm{mg} / \mathrm{kg}$ dose and are interpreted in the context of data relating male and female copulatory behavior to brain monoaminergic function.

Recent data have revealed considerable parallels between drug effects on copulatory behavior in male and female rats. In general. drugs which increase levels of brain monoamines. particularly serotonin. have been shown to inhibit lordotic behavior in female rats, while drugs which reduce such levels facilitate the display of lordosis (e.g.. Meyerson. 1964: Zemlan. Ward, Crowley, \& Margules. 1973). In parallel fashion. p-chlorophylalanine. reserpine, and tetrabenazine, all of which decrease brain monoamine levels. facilitate male copulatory behavior (e.g.. Dewsbury \& Davis. 1970; Dewsbury. 1971. 1972: Salis \& Dewsbury. 1971). Monoamine oxidase (MAO) inhibitors. which increase brain monoamine levels, retard copulatory behavior (Dewsbury. Davis. \& Jansen. 1972).

Imipramine is a tricyclic antidepressant drug which has several effects. including potentiation of monoamine function through interference with reuptake in central monoaminergic neurons. Meyerson (1966) found that imipramine inhibited estrous behavior in estrogen-primed female rats given progesterone, reserpine, or tetrabenazine. Spontaneous activity was normal. The present research was designed to examine the possibility that a parallel retardation of copulatory behavior may follow administration of imipramine to male rats. Such a possibility is suggested by the report of Handley (1966) that imipramine produced a depression of the penile erections that normally follow electrical stimulation to the septal area and anterior hypothalamus of squirrel monkeys. Inhibitory effects on sexual function in human males also have been reported (Greenberg. 1965: Simpson. Blair. \& Amuso. 1965).

*This research was supported by Grants GB-12941 and GB-28554 from the National Science Foundation. We thank the Geigy Chemical Company. Ardsley. N.Y.. for providing the imipramine hydrochloride (Tofranil). Hormones were provided through the courtesy of the Schering Corporation. Bloomfield, N.J. Deirdre Lovecky was a trainee of the Center for Neurobiological Sciences of the University of Florida under Grant NIH-MH-10320 to the University of Florida. Please address reprint requests to $D$. A. Dewsbury. Department of Psychology. University of Florida. Gainesville, Fla. 32601.

\section{METHOD}

The S、 wire 22 male Long-Evans rats purchased from a commercial upplier and approximately 125 days old at the beginning of pretesting. They were mated with 27 females of the same age and itrain. All animals were without prior copulatory experience.

Tests were conducted in Plexiglas arenas. $76-84 \mathrm{~cm}$ in diam and $66 \mathrm{~cm}$ high. The arenas were placed on wooden platforms covered with a commercially produced litter material. Copulatory events were recorded manually on an Esterline-Angus operations recorder.

Prior to the beginning of the experiment. all rats were given extensive handling and exploratory experience in the arenas. Next. each rat received pretests of copulatory behavior in order to permit selection of animals which would copulate and to minimize effects of experience in the experiment itself. Twenty-two of the males met the criterion of attaining two ejaculations on each of two pretests. Two of these males died before completion of testing.

In the experiment itself, each male received three tests of copulatory behavior spaced 4 weeks apart. Prior to one test. $10 \mathrm{mg} / \mathrm{kg}$ imipramine hydrochloride (Tofranil) dissolved in saline was administered IP. Prior to a second test, a dose of $25 \mathrm{mg} / \mathrm{kg}$ imipramine was given. A saline injection preceded a third test for each animal. The injection-test interval was 67-223 min. Three or four rats were assigned to each of the six possible running orders in a balanced design.

The rats were maintained on a reversed light-dark cycle. with tests conducted in the room in which the rats were housed. Tests were conducted in $\operatorname{dim}$ white light and were initiated approximately $4 \mathrm{hr}$ after light offset. Males were permitted $5 \mathrm{~min}$ in the arenas prior to beginning the test. Tests were begun with the introduction of the female and terminated after $30 \mathrm{~min}$ if there were no intromissions or after occurrence of the third ejaculation if copulation was initiated.

Females were brought into estrus with administration of $0.1 \mathrm{mg}$ estradiol benzoate approximately $72 \mathrm{~h}$ prior to testing and with $1.0 \mathrm{mg}$ progesterone $3 \mathrm{~h}$ before testing. Females were tested with nonexperimental males before each session in order to assess receptivit:

Copulatory behavior in rats occurs as groups or "series" of mounts and intromissions. with each series terminated by an ejaculation. Standard measures of copulatory behavior were taken: mount latency (ML)-time from introduction of the female until the first mount with thrusting; intromission latency (IL)-latency from introduction of the female until the first vaginal intromission; ejaculation latency $(E L)$-latency from the first intromission of a series until the terminal ejaculation: intromission frequency (IF)-number of intromissions in a series: mount frequency (MF)-number of mounts with pelvio thrusting. but without intromission in a series: mean interintromission interval (MIII)-mean interval separating intromissions of a series: postejaculatory interval (PEI)-interval between an ejaculation and the resumption of copulation as indicated by the next intromission. The series is indicated by a hyphen and appropriate number in the abbreviation (e.g. IF -2).

\section{RESULTS}

Mean scores on all measures and inferential statistics are presented in Table 1. Two-way analyses of variance with repeated measures were conducted for all measures. Data from four males had to be eliminated because they did not copulate on all tests. Significant effects of 
Table 1

Effects of Imipramine on Copulatory Behavior

\begin{tabular}{lrrrrr}
\hline Measure & Saline & $\begin{array}{r}10 \\
\mathrm{mg} / \mathrm{kg}\end{array}$ & $\begin{array}{r}25 \\
\mathrm{mg} / \mathrm{kg}\end{array}$ & \multicolumn{1}{c}{$\mathrm{F}$} & $\mathrm{p}$ \\
\hline ML & 8.3 & 15.8 & 62.4 & 2.90 & n.s. \\
IL & 38.7 & 33.8 & 157.8 & 1.99 & n.s. \\
EL-1 & 579.9 & 545.3 & 691.7 & 1.35 & n.s. \\
EL-2 & 256.6 & 197.5 & 247.6 & 0.64 & n.s. \\
EL-3 & 323.2 & 333.9 & 311.8 & 0.09 & n.s. \\
IF-1 & 11.6 & 9.2 & 6.8 & 3.99 & $<.05$ \\
IF-2 & 4.7 & 4.1 & 3.2 & 4.08 & $<.05$ \\
IF-3 & 5.6 & 4.9 & 3.2 & 6.78 & $<.01$ \\
MF-1 & 8.9 & 5.9 & 6.9 & 0.47 & n.s. \\
MF-2 & 4.0 & 1.9 & 2.9 & 0.54 & n.s. \\
MF-3 & 4.8 & 4.9 & 4.6 & 0.00 & n.s. \\
MIII-1 & 50.5 & 62.7 & 97.9 & 10.57 & $<.01$ \\
MIII-2 & 54.3 & 48.4 & 77.4 & 8.78 & $<.01$ \\
MIII-3 & 55.7 & 60.4 & 90.7 & 4.61 & $<.05$ \\
PEI-1 & 354.3 & 385.0 & 460.4 & 5.97 & $<.01$ \\
PEI-2 & 434.9 & 480.0 & 507.6 & 4.53 & $<.05$ \\
\hline
\end{tabular}

imipramine were found for MIII. PEI, and IF for all three series. In each case, the latencies were increased and the number of intromissions to attain ejaculation were decreased by imipramine. No other measures showed significant effects. Newman-Keuls procedures were used to test paired comparisons for significant measures (Winer, 1962). The comparison of saline with the $25-\mathrm{mg} / \mathrm{kg}$ dose was significant at at least the .05 level for all measures examined. Saline and the $10-\mathrm{mg} / \mathrm{kg}$ dose never differed significantly. The $10-$ and $25-\mathrm{mg} / \mathrm{kg}$ doses produced significantly different effects for MIII-1, MIII-2, MIII-3, PEI-1, and IF-3. There was no apparent consistent relationship between injection-test interval and behavioral effect.

\section{DISCUSSION}

The effects of imipramine were clear and consistent in all series. Dose-response data were orderly. The intervals between intromissions and the intervals between ejaculation and the resumption of mating all were consistently increased. Thus, it is clear that imipramine produces a retardation in these temporal parameters of copulatory behavior. This inhibitory effect is further seen in the data from the few rats that had to be eliminated from the data analysis for failure to complete all tests. One male failed to copulate under any condition; two males failed to copulate under both drug conditions; and one male failed to copulate with the $10-\mathrm{mg} / \mathrm{kg}$ dose.

Imipramine also produced reliable decreases in the number of intromissions preceding ejaculation in all three series. This effect is difficult to interpret. Prolongation of interintromission intervals through experimental intervention produces a reduction in IF (see Larsson, 1956: Bermant. 1964). Where reductions in IF are produced in the same series as increases in MIII, the possibility cannot be excluded that the changes in IF are secondary to the prolongations of MIII. Such an interpretation was proposed regarding the effects of alcohol on male copulatory behavior (Dewsbury, 1967). On this interpretation, the primary effects of imipramine would be to retard the temporal parameters of copulatory behavior, and the changes of IF would be secondary phenomena. However. it is also quite possible that the reduction in IF is a real and primary effect of the drug. With this combination of effects. the alternative possibilities are not distinguishable.
The mechanism through which imipramine produces these behavioral effect camnot be established from the present data. Imipramine has weak anticholinergic properties (Rech \& Moore. 1971). As copulatory behavior is distupted by alterations of the cholinergic system (Leavitt. 1969), the possibility of cholinergic mediation cannot be excluded. However. as imipramine's anticholinergic effects are weak, this seems unlikely. The effects of imipramine on brain monoamines appear more substantial. Imipramine blocks the uptake of serotonin (e.g.. Carlsson. Fuxe. \& Lingerstedt. 1968). As serotonin is implicated in the regulation of copulatory behavior (e.g. Salis \& Dewsbury, 1971), this represents a possible mechanism. Within the time span of the present injection-test intervals. much imipramine is metabolized to desmethylimipramine (DMI) (Dingell. Sulser. \& Gillette. 1964: Bickel \& Weder. 1968). As both DMI and imipramine block catecholamine uptake, this provides another possible mechanism. Determination of whether all or some of these mechanisms are involved in mediating the observed effects must await further biochemical analyses.

Although imipramine is a complex drug that produces a variety of pharmacological effects in rats, its effects on copulatory behavior were appreciable and consistent across series. The most clearly interpretable effect of the drug was a retardation of the temporal parameters of copulation. MIII and PEI. For at least these measures. the inhibitory effects of imipramine on the copulatory behavior of male rats resemble the effects of MAO inhibitors (Dewsbury et al. 1972) and parallel the effects of both imipramine and the MAO inhibitors on lordotic behavior in female rats (Meyerson. 1964. 1966: Lindstrom 1970).

\section{REFERENCES}

Bermant, G. Effects of single and multiple enforced intercopulatory intervals on the sexual behavior of male rats. Journal of Comparative \& Physiological Psychology, 1964,57. 476-481.

Bickel, M. H., \& Weder, H. J. The total fate of a drug: Kinetics of distribution, excretion, and formation of 14 metabolites in rats treated with imipramine. Archives Internationales de Pharmacodynamie et Therapie, 1968, 173, 433-463.

Carlsson, A., Fuxe, K., \& Ungerstedt, U. The effect of imipramine of central 5 -hydroxytryptamine neurons. Journal of Pharmacy \& Pharmacology, 1968, 20, 150-151.

Dewsbury, D. A Effects of alcohol ingestion on copulatory behavior of male rats. Psychopharmacologia, 1967, 11, 276-281.

Dewsbury, D. A. Copulatory behavior of male rats following reserpine administration. Psychonomic Science, 1971, 22 177-179.

Dewsbury, D. A. Effects of tetrabenazine on the copulatory behavior of male rats. European Journal of Pharmacology. $1972,17,221-226$.

Dewsbury, D. A., \& Davis, H. N. Effects of reserpine on the copulatory behavior of male rats. Physiology \& Behavior. $1970,5,1331-1333$.

Dewsbury, D. A.. Davis, H. N., \& Jansen, P. E. Effects monoamine oxidase inhibitors on the copulatory behavior of male rats. Psychopharmacologia, 1972, 24, 209-217.

Dingell, J. V., Sulser, F., \& Gillette, J. R. Species differences in the metabolism of imipramine and desmethylimipramine (DMI). Journal of Pharmacology \& Experimental Therapeutics, $1964,143,14-22$

Greenberg, H. R. Erectile impotence during the course of Tofranil therapy. American Journal of Psychiatry, 1965, 121 , 102.

Handley, C. D. Penile erection by brain stimulation in the squirrel monkey: Effects of drugs. Federation Proceedings, $1966,25,386$.

Larsson, $\mathrm{K}$. Conditioning and sexual behavior in the male albino rat. Stockholm: Almqvist \& Wiksell, 1956.

Leavitt, F. I. Drug-induced modifications in sexual behavior and open field locomotion of male rats. Physiology \& Behavior, $1969,4,677-683$.

Lindstrom, L. H. The effect of pilocarpine in combination with monoamine inhibitors, imipramine or desmethylimipramine on oestrous behaviour in female rats. Psychopharmacologia, 1970, 17, 160-168.

Meverson, B. J. Central nervous monoamines and hormone 
Induced estrus behaviour in the spaved rat. Arta Phrsiologica Scandinavica, 1964. Suppl. 241, 1-32

leversin $\mathrm{B}$. antidepressant drugs on estrus behaviour in ovariectomised rats activated by progesterone. reserpine. or tetrabenazine in combination with estrogen. Acta Physiologica Scandinavica. $1966,67,411-422$

Rech R H. \& Noore, K. E. An introduction to psyourmo York: Raven Press, 1971

Salis, P. J. \& Dewsburv. D. A. p-Chlorophenvlalanine facilitates alis, P. J.. \& Dewsbury. D. A. p-Chlorophentalanine facilitates
copulatory behaviour in male rats. Nature. 1971, 232. 400-401.
Simpson. G. M.. Blair, J. H.. \& Amuso. D. Effects of anti-depressants on genito-urinary function. Diseases of the Vervous System, 1965, 26, 787-789.

winer $\mathrm{B}$ Statistical principles in experimental design. New York: McGraw-Hill. 1962.

Zemlan. F. P.. Ward. I. L.. Crowley, W. R.. \& Margules. D. L. Activation of lordotic responding in female rats by suppression of serotonergic activity. Science. 1973, 179. 1010-1011.

(Received for publication June 11, 1973.)

\section{Effects of prolonged training, differential housing, and response prevention on persisting avoidance in rats*}

\section{FREDERIC J. SAUTTER and LARRY D. REID Bradley Liniversitn, Peoria. Ill. 61606}

Eight groups of five rats were trained to jump to a retractable shelf to avoid footshock. Before footshock was terminated and tests conducted for extinction of responding, one-half were trained for about 35 trials and one-half for about 310 trials. For 50 days prior to training, one-half of the rats lived individually in small

* This study was supported by Bradley's Board for Research which administers NSF Grant GU 3320. This study was part of a research program codirected by $H$. $R$. Miller who is now at Southern Illinois University. cages and one-half lived in large cages, 12 rats a cage. These two pretesting factors, plus a factor of presence or absence of response prevention given just before testing for extinction of avoidance, combined to vield a 2 by 2 by 2 experimental design. Rats took reliably longer to extinguish avoidance if they were trained more and if they were from group housing. The demonstration that pretraining housing is a reliable source of variance suggests that this factor should be controlled in studies of deconditioning of avoidance.

Baum (1965.1970) has described a procedure for efficiently training rats to avoid and has tested a number of ways to determine the most efficient ways to reduce perseveration of responding after footshock is 